\title{
UNA PERSPECTIVA PANORÁMICA Y REGIONAL SOBRE LA MEDIACIÓN LABORAL Y EN MATERIA DE CONSUMO EN ESPAÑA
}

\author{
A PANORAMIC AND REGIONAL PERSPECTIVE ON LABOR AND CONSUMPTION \\ MEDIATION IN SPAIN
}

\section{Carlos Teruel Fernández}

Profesor de Derecho del Trabajo y de la Seguridad Social UCAM. Doctorando derecho laboral mail: cteruel@ucam.edu

Convidado

RESUMO: En España, en el contexto laboral donde trabajadores y sus organizaciones junto con los empresarios son protagonistas, observamos como se está desarrollando la normativa que regirá sus relaciones. Respecto al consumo, sin embargo, es el Estado el que, siguiendo las directrices de la Unión Europea, está desarrollando una legislación que pretende cubrir la táctica necesidad que se refiere a su ámbito procedimental. En el presente artículo, revisaremos cuál es la situación normativa actual de esta figura en las materias señaladas y su importancia en la práctica, tanto a nivel estatal como la experiencia particular de la Región de Murcia.

Palavras-chave: Mediación; ADR; Derechos Fundamentales; Laboral; Consumo; Extrajudicial; Conflicto; Negociación colectiva; Arbitraje.

\begin{abstract}
In Spain, in the labor context where workers, and their organizations together with employers are protagonists, we observe how the regulations that will govern their relationships are being developed. Regarding consumption, however, it is the State that, following the guidelines of the European Union, is developing legislation that covers the tactical necessity that refers to its procedural scope. In this article, we will review the current regulatory situation of this figure in the aforementioned matters and its importance in practice, both at the state level and the particular experience of the Region of Murcia.
\end{abstract}

Keywords: Mediation; ADR; Fundamental Rights; Labor; Consumption; Extrajudicial; Conflict; Collective Bargaining; Arbitration.

SUMÁRIO: 1. MEDIACIÓN LABORAL. 1.1. Aproximación desde la generalidad. 1.2. Propuestas particulares: el caso del V Acuerdo sobre Solución Autónoma de Conflictos Laborales. 1.3. Significado y alcance del II Acuerdo sobre Solución Extrajudicial de Conflictos Laborales en la Región de Murcia y su Reglamento de Aplicación. 2. MEDIACIÓN EN MATERIA DE CONSUMO. 2.1. Cuestiones generales de la mediación en materia de consumo, fijación de conceptos y planteamientos. 2.2 El régimen jurídico y su aplicación práctica. 2.3. Las Oficinas Municipales de Información al Consumidor. 3. CONCLUSIONES. 4. BIBLIOGRAFIA. 


\section{MEDIACIÓN LABORAL}

\subsection{Aproximación desde la generalidad}

Desde que la Constitución Española de 1978 reconociera el derecho de los trabajadores y empresarios a adoptar medidas de conflicto colectivo, la configuración de procedimientos efectivos y ágiles para la solución extrajudicial de conflictos entre trabajadores y empresarios, así como entre sus organizaciones representativas ha ido protagonizando las sucesivas modificaciones normativas, así como la creación y modificación de numerosos acuerdos y convenios colectivos.

El desarrollo de los derechos fundamentales vinculados al conflicto colectivo se conecta directamente con el contenido de la Constitución española, en cuanto ésta regula los derechos de sindicación y para fundar sindicatos, junto con el derecho de huelga. Estos derechos se encuentran vinculados directamente con las medidas de conflicto colectivo, herramientas que los sindicatos de trabajadores y las asociaciones de empresarios utilizan para la defensa de sus pretensiones e intereses socioeconómicos. En esta materia, se pone de manifiesto una clara voluntad de ofrecer soluciones alternativas a través de, como indica VIANA LÓPEZ, "fórmulas convencionales de solución de conflictos fruto de la negociación colectiva que se desenvuelven principalmente en el ámbito de los conflictos colectivos", lo que se ha ido plasmando tanto a nivel nacional como regional en virtud de los distintos acuerdos a los que han llegado los sindicatos más representativos y las asociaciones empresariales con mismo grado de representación. La protección uti socius se encuentra asegurada. Revisemos a continuación que ocurre cuando plantemos la circunstancia uti singuli. Podemos decir que el marco constitucional garantiza y protege el contenido esencial de los derechos vinculados al ámbito laboral en la tensión que se da entre empleadores y empleados. Así pues, si bien las soluciones extrajudiciales de conflictos están indicadas principalmente para los conflictos colectivos, ello no obsta para que en un conflicto individual las partes puedan someterse al correspondiente proceso de mediación o arbitraje. De hecho, pese a que en determinadas ocasiones la conciliación administrativa o mediación previa es también obligatoria para los trabajadores de manera individual, lo habitual en que estos conflictos individuales se inicien con la presentación de la papeleta de conciliación y la misma sea intentada ante el oportuno Servicio de Mediación, arbitraje y Conciliación, con ello quedan asegurados los posibles derechos fundamentales de titularidad individual que estuvieran involucrados en el conflicto .

En concreto, parece que la aplicación de la mediación resulta beneficiosa y oportuna pues, como señala ARASTEY SAHÚN, "ofrece flexibilidad y adaptabilidad a las especiales circunstancias de cada caso; además la confidencialidad propia de la mediación permite un enfoque más honesto y sincero de las posturas de las partes". En este sentido, en España, la Ley 5/2012, de 6 de julio, de mediación en asuntos civiles y mercantiles, haciendo carne el verbo, la define como "aquel medio de solución de controversias, cualquiera que sea su denominación, en que dos o más partes intentan voluntariamente alcanzar por sí mismas un acuerdo con la intervención de un mediador", tras lo cual excluye de su ámbito de aplicación a la mediación laboral, probablemente por las consideraciones arriba apuntadas en relación con los derechos fundamentales en los que no cabe la disponibilidad ni la cesión en su contenido esencial, recordando a KANT "están fuera el comercio de los hombres". Con todo, esta vía se concreta en el nombramiento por las partes enfrentadas de un mediador con la pretensión de lograr una solución consensuada y vinculante. En palabras de la Organización Internacional del Trabajo "La fuerza de la mediación reside, por tanto, en el hecho de que cada una de las partes cree en la posibilidad de que la otra asuma medidas de fuerza, y en el convencimiento de cada una que el acuerdo es preferible a dichas medidas, por lo que ambas se hallan en condiciones de realizar concesiones para llegar a un acuerdo ante el tercero".

En este sentido, la mediación, rompiendo con su carácter voluntario, podría ser impuesta ya que el intento de conciliación o mediación ante el servicio administrativo correspondiente o el 
órgano que asuma estas funciones conciliadoras o mediadoras es requisito previo indispensable para la tramitación del procedimiento judicial social.

Salvando el mencionado carácter obligatorio, que se corresponde con un simple apunte cuyo análisis excede las reflexiones aquí vertidas, destacamos que en las disposiciones sobre controversias colectivas referidas en el Estatuto de los Trabajadores, como la movilidad geográfica, las modificaciones sustanciales de las condiciones de trabajo, la suspensión del contrato o reducción de jornada por causas económicas, técnicas, organizativas o de producción o derivadas de fuerza mayor y el despido colectivo, se pone de manifiesto que el empresario y la representación de los trabajadores pueden acordar en cualquier momento la sustitución del periodo de consultas por la aplicación del procedimiento de mediación o arbitraje que sea de aplicación según el ámbito de la empresa, procedimiento que deberá desarrollarse dentro del plazo máximo del indicado periodo de consultas. Al respecto, ha de subrayarse que el pacto que permitiera un cese, límite o recorte a los derechos laborales desnaturalizaría los derechos fundamentales de los trabajadores, careciendo de validez en el ordenamiento jurídico español a pesar de que es posible acudir voluntariamente a esta vía cuando así lo deciden las partes de común acuerdo y, por la naturaleza jurídica de la pretensión, el acuerdo pudiera tener eficacia jurídica.

\subsection{Propuestas particulares: el caso del V Acuerdo sobre Solución Autónoma de Conflictos Laborales}

En España, actualmente está vigente el V Acuerdo sobre Solución Autónoma de Conflictos Laborales, suscrito el 7 de febrero de 2012 entre la Confederación Sindical de Comisiones Obreras y por Unión General de Trabajadores, por un lado, y por la Confederación Española de Organizaciones Empresariales y la Confederación Española de Pequeñas y Medianas Empresas, por otro. Como hemos comentado, tanto sindicatos como asociaciones empresariales están facultadas para la realización de este tipo de acuerdos. Y en el presente caso, lo han hecho por quinta vez desde que se firmara el primer Acuerdo de Solución Extrajudicial de Conflicto el 25 de enero de 1996.

Como afirma FERNÁNDEZ-COSTALES MUÑIZ, estos acuerdos han supuesto "un paso básico y fundamental en la modernización del sistema español de relaciones laborales, en tanto en cuanto potencian la autonomía colectiva y aporta dosis de racionalización y ductilidad a la dinámica laboral, favoreciendo la solución pronta y adecuada (por el concierto de las partes implicadas) de los conflictos profesionales".

El V Acuerdo sobre Solución Autónoma de Conflictos Laborales tiene como objeto el mantenimiento y desarrollo de un sistema autónomo de solución de conflictos colectivos laborales surgidos entre empresarios y trabajadores o sus respectivas organizaciones representativas, excluyéndose los conflictos que versen sobre Seguridad Social y aquéllos en lo que sea parte el Estado, las Comunidades Autónomas, las entidades locales y cualesquiera otras entidades de Derecho Público.

Pese a que el V Acuerdo sobre Solución Autónoma de Conflictos Laborales tiene carácter general y, por tanto, sería de aplicación a todas las empresas de ámbito nacional o superior al de una Comunidad Autónoma, el mismo aclara que por convenio o acuerdo colectivo sectorial estatal o convenio de empresa, grupo de empresa o empresas vinculadas, estas empresas podrán establecer sistemas propios de solución extrajudicial de los conflictos señalados en el propio Acuerdo sobre Solución Autónoma de Conflictos Laborales, no integrados en el Servicio Interconfederal de Mediación y Arbitraje. Aún así, en cualquier momento, podrían adherirse de nuevo a las disposiciones del Acuerdo.

Para poder acogerse al procedimiento de mediación señalado en el Acuerdo, el conflicto laboral deberá ser uno de los contemplados en su articulado, entre los que encontramos: 
a. Conflicto colectivo de interpretación y aplicación de una norma estatal, convenio colectivo, cualquiera que sea su eficacia, pactos o acuerdos de empresa, o de una decisión empresarial de carácter colectivo.

b. Controversias en las comisiones paritarias de los convenios colectivos que conlleven el bloqueo en la adopción de acuerdos, para la resolución de las funciones que legal o convencionalmente tengan atribuidas.

c. Conflictos surgidos durante la negociación de un convenio que conlleven su bloqueo.

d. Conflictos surgidos durante la negociación de un acuerdo o pacto colectivo, que conlleven el bloqueo de la negociación correspondiente.

e. Conflictos derivados de discrepancias surgidas en el periodo de consultas exigido en los procesos colectivos de movilidad geográfica, modificaciones sustanciales de condiciones de trabajo, reducciones o suspensiones de jornada o despido colectivo.

f. Conflictos que motiven la impugnación de convenios colectivos, de forma previa al inicio de la vía judicial.

g. Conflictos derivados de discrepancias durante la negociación de los acuerdos de inaplicación de determinadas condiciones de trabajo pactadas en los convenios colectivos sectoriales, cuando dichos convenios contemplen su inaplicación negociada.

h. Conflictos que den lugar a la convocatoria de huelga o que se susciten sobre la determinación de los servicios de seguridad y mantenimiento en caso de huelga.

Para la resolución de estos conflictos, se establecen dos procedimientos: el de mediación y el de arbitraje. Centrados en el procedimiento de mediación, éste resulta obligatorio en los casos señalados en el propio Acuerdo siempre que lo demande una de las partes, salvo en los casos en que se exija acuerdo. Así pues, la mediación, que se presenta ante el Servicio Interconfederal de Mediación y Arbitraje, sustituye la conciliación administrativa previa prevista en la Ley Reguladora de la Jurisdicción Social.

La mediación se desarrolla de forma preferente por un órgano unipersonal o, si lo exigieran las partes, por uno colegiado de dos o tres mediadores, que guían a las partes para solventar sus diferencias. El mediador o mediadores son designados documentalmente por las propias partes, quienes también harán constar las divergencias existentes y las cuestiones sobre las que versará su función. En este sentido, ha de tenerse en cuenta que la mediación es preceptiva como requisito preprocesal para la interposición de demandas de conflicto colectivo ante la jurisdicción social por cualquiera de las partes y sustituye a la conciliación administrativa previa. Respecto a la convocatoria de huelga, interesa aquí destacar que se requerirá, con anterioridad a su comunicación formal, haber agotado el procedimiento de mediación. De hecho, la iniciación del procedimiento de mediación, y mientras éste dure, impide la convocatoria de huelga, de cierre patronal, así como del ejercicio de acciones judiciales o administrativas.

El procedimiento regulado en el V Acuerdo sobre Solución Autónoma de Conflictos Laborales comienza con la presentación de un escrito dirigido al Servicio Interconfederal de Mediación y Arbitraje, que deberá contener: la identificación de las partes, el objeto del conflicto, el colectivo de trabajadores afectados y el ámbito territorial del mismo, acreditación de la intervención de la Comisión Paritaria, el mediador u órgano colegiado de mediación (designados de entre los mediadores que figuren en la lista del Servicio Interconfederal de Mediación y Arbitraje), y el domicilio, fecha y firma de los sujetos legitimados.

El mediador o mediadores designados deberán ser ajenos al conflicto concreto en que actúan, sin que puedan concurrir intereses personales o profesionales directos susceptibles de alterar o condicionar su actividad mediadora.

En los conflictos planteados con ocasión de la interpretación y aplicación de un convenio, acuerdo o pacto colectivo sectorial cuya Comisión Paritaria tenga encomendadas funciones de mediación, podrán ser designados como mediadores los miembros de la misma. 
Promovida la mediación y durante su tramitación, las partes deben abstenerse de adoptar cualquier otra medida dirigida a la solución del conflicto.

La actuación del mediador o mediadores comienza nada más sean designados según los trámites que consideren apropiados. Para ello, recabarán la información que estimen necesaria, garantizando su confidencialidad.

El mediador o mediadores deben convocar una comparecencia en la que intentarán que las partes alcancen un acuerdo. Los mediadores moderarán el debate y concederán a las partes las intervenciones que considere necesarias. Tras ello, formularán propuestas para solucionar el conflicto que las partes podrán aceptar o rechazar. Si no ha habido acuerdo en la comparecencia, los mediadores podrán realizar nuevas propuestas dentro del plazo de 10 días tras la misma, que igualmente podrán ser o no acogidas. Si los mediadores propusieran someter el asunto a arbitraje y las partes aceptaran, se terminaría el proceso de mediación.

El procedimiento de mediación puede finalizar con o sin acuerdo. Si se finalizara con acuerdo, hemos de diferenciar si se ha alcanzado bien de forma concreta o general. En procedimientos colectivos de movilidad geográfica, modificaciones sustanciales de condiciones de trabajo, medidas laborales tras sucesión de empresas, reducciones o suspensiones de jornada, despido colectivo o acuerdos de no aplicación de alguna cláusula del convenio colectivo, el acuerdo tendrá la misma eficacia que lo pactado en el acuerdo tras el periodo de consultas. En los demás conflictos laborales, tendrá la misma eficacia que lo pactado en convenio colectivo, siendo objeto de depósito y registro conforme a lo indicado en el Estatuto de los Trabajadores.

El acuerdo alcanzado sólo podrá ser impugnado por las partes y por quienes pudieran sufrir perjuicio por aquél en el plazo de 30 días ante el juzgado o tribunal al que hubiera correspondido el conocimiento del asunto objeto de la mediación, mediante el ejercicio de la acción de nulidad por las causas que invalidan los contratos o por los posibles perjudicados con fundamento en su ilegalidad o lesividad.

Si no se alcanzara acuerdo alguno, los mediadores levantarán acta en la que registrarán la ausencia de acuerdo, las propuestas formuladas y las razones alegadas por las partes para justificar su no aceptación.

\subsection{Significado y alcance del II Acuerdo sobre Solución Extrajudicial de Conflictos Laborales en la Región de Murcia y su Reglamento de Aplicación}

En España, organizada territorialmente en Comunidades Autónomas, esta normativa ha sido expresión de las representaciones sindicales y patronales autonómicas que han diseñado su propio Acuerdo en materia de solución extrajudicial de conflictos, siendo de aplicación en el respectivo ámbito territorial y para las materias señaladas en los mismo Acuerdos. Sirva de ejemplo el II acuerdo realizado por la Confederación Regional de Organizaciones Empresariales Murcianas, por un lado, y los sindicatos más representativos, es decir, el Sindicato de la Unión General de Trabajadores y de Comisiones Obreras, por otro, sobre Solución Extrajudicial de Conflictos Laborales en la Región de Murcia, que se aprobó junto a su Reglamento de aplicación.

En el ámbito regional, al igual que el V Acuerdo sobre Solución Autónoma de Conflictos Laborales, el II Acuerdo sobre Solución Extrajudicial de Conflictos Laborales en la Región de Murcia tiene por objeto potenciar, desarrollar y mejorar el sistema extrajudicial de solución de conflictos surgidos entre empresarios y trabajadores o sus respectivas organizaciones representativas, aunque a diferencia del anterior, este Acuerdo es de aplicación en el territorio de la Región de Murcia y será de aplicación para todos los conflictos surgidos entre las partes legitimadas de cualquier sector de actividad que estén sometidas a un convenio colectivo de ámbito regional o inferior. Sin embargo, también podrán someterse las partes cuando, pese a estar afectadas por convenio de ámbito superior, el conflicto afecte únicamente a centros de trabajo ubicados en la Región de Murcia. 
También de forma opuesta a lo que ocurre con el V Acuerdo sobre Solución Autónoma de Conflictos Laborales, que tiene carácter general, la aplicación de las disposiciones contenidas en el II Acuerdo sobre Solución Extrajudicial de Conflictos Laborales en la Región de Murcia está condicionada a que las partes legitimadas suscriban un instrumento de ratificación o adhesión para formar parte de este Acuerdo. Así, las mismas podrán someterse a los procedimientos de mediación y arbitraje recogidos en el II Acuerdo sobre Solución Extrajudicial de Conflictos Laborales en la Región de Murcia los siguientes conflictos laborales:

a. Los conflictos colectivos de interpretación y aplicación de una norma estatal, convenios colectivos, acuerdos o pactos colectivos, o una decisión o práctica de empresa.

b. Los conflictos ocasionados por discrepancias surgidas durante la negociación de un Convenio Colectivo u otro acuerdo o pacto colectivo.

c. Los conflictos que desemboquen en la convocatoria de una huelga o que se susciten sobre la determinación de los servicios de seguridad y mantenimiento en caso de huelga.

d. Los conflictos derivados de discrepancias surgidas en el periodo de consultas exigido por el Estatuto de los Trabajadores.

Si bien en el ámbito estatal la solicitud de mediación se solicitaba ante el Servicio Interconfederal de Mediación y Arbitraje, en el ámbito de la Región de Murcia, dichas solicitudes se harán ante la Oficina de Resolución de Conflictos Laborales, creada por las partes firmantes del II Acuerdo sobre Solución Extrajudicial de Conflictos Laborales en la Región de Murcia. La Oficina de Resolución de Conflictos Laborales acogerá las demandas de mediación y arbitraje que se deriven del Acuerdo y, en el supuesto que los convenios colectivos o acuerdos sectoriales hayan creado órganos específicos de mediación o arbitraje, quedaran integrado en esta Oficina, siempre que en su ámbito hayan asumido el Acuerdo.

Siguiendo el modelo de mediación que se da en el Estado, a nivel autonómico se solicita por escrito, haciendo constar las divergencias existentes, pero en este caso cada una de las partes deberá seleccionar un mediador y presentar el escrito ante la Oficina de Resolución de Conflictos Laborales, Oficina ante la que podrán delegar la designación de mediador o mediadores. La designación de los mediadores se producirá entre las personas incluidas en las listas aprobadas por el Comité Paritario Regional, que comprenderán aquellos mediadores propuestos por las organizaciones firmantes del Acuerdo. También podrán las partes recurrir al órgano específico de mediación incorporado a la Oficina de Resolución de Conflictos Laborales.

En cuanto a la forma de actuar de los mediadores y a las posibles formas de finalización del procedimiento, el II Acuerdo sobre Solución Extrajudicial de Conflictos Laborales en la Región de Murcia en poco difiere de lo dispuesto en el V Acuerdo sobre Solución Autónoma de Conflictos Laborales. Si bien no se dispone nada sobre la celebración de una comparecencia, el mediador puede realizar propuestas para la solución del conflicto, incluido el sometimiento del asunto a arbitraje, y las partes decidirán si aceptar o rechazar las mismas. El acuerdo alcanzado tendrá los mismos efectos que a nivel estatal, formalizándose por escrito y presentando copia a la autoridad laboral competente. Si no hubiere acuerdo, se levantará igualmente la oportuna acta recogiendo las propuestas y los motivos del rechazo de las mismas.

Pese a ser de ámbito inferior al estatal, estos acuerdos también sustituyen el trámite obligatorio de conciliación previsto el la Ley Reguladora de la Jurisdicción Social. 


\section{MEDIACIÓN EN MATERIA DE CONSUMO}

\subsection{Cuestiones generales de la mediación en materia de consumo, fijación de conceptos y planteamientos}

Como hemos comprobado, la normativa vigente en materia de mediación excluía expresamente la aplicación de su contenido para la mediación en el ámbito laboral. Esta exclusión se realizó igualmente para la mediación en materia de consumo hasta que ésta fue suprimida por la Ley 7/2017, de 2 de noviembre, por la que se incorporó al ordenamiento jurídico español la Directiva 2013/11/CE, del Parlamento Europeo y del Consejo, de 21 de mayo de 2013, relativa a la resolución alternativa de litigios en materia de consumo que pretende el fomento de esta técnica.

Ciertamente, la mediación en materia de consumo obtiene mayor protagonismo desde la aprobación de la Directiva del año 2012, cuyo objeto se centra en poner al servicio del mercado interior europeo una herramienta que ofrezca las debidas garantías a los consumidores y garantice su buen funcionamiento. Mediante la mediación en el ámbito comercial, los consumidores pueden resolver sus controversias con la ayuda de entidades mediadoras independientes, imparciales, transparentes, efectivas, rápidas y justas.

En España, la Ley 7/2017, si bien incorpora el principal contenido de la Directiva Europea, sólo pretende establecer los requisitos que buscan la armonización de la calidad de las entidades de resolución alternativa a las que pueden concurrir los consumidores y los empresarios para la solución de sus litigios, sin que regule ni desarrolle los procedimientos de resolución alternativa de conflictos. En concreto, tiene como objeto determinar los requisitos que deben reunir las entidades para ser acreditadas, regular el procedimiento para obtener dicha acreditación, establecer las obligaciones que éstas deberán asumir y garantizar a los consumidores el conocimiento de la existencia de estas entidades para la defensa de sus derechos.

Una breve revisión conceptual referida al significado y alcance de consumidor y comerciante entiende que lo son bajo el amparo de la Directiva aquellas personas físicas que actúen con un propósito ajeno a su actividad comercial, empresarial, oficio o profesión, pero también lo son las personas jurídicas y las entidades sin personalidad jurídica que actúen sin ánimo de lucro en un ámbito ajeno a una actividad comercial o empresarial. Por otro lado, se considera empresario o comerciante a toda persona física o jurídica, ya sea privada o pública, que actúe directamente o a través de otra persona en su nombre o siguiendo sus instrucciones, con un propósito relacionado con su actividad comercial, empresarial, oficio o profesión.

\subsection{El régimen jurídico y su aplicación práctica}

Actualmente, no existe una regulación específica sobre el procedimiento de mediación en materia de consumo. Sólo podemos encontrar cierto atisbo de su configuración legal en el Real Decreto 231/2008, de 18 de febrero, por el que se regula el Sistema Arbitral de Consumo, es decir, dentro de otro sistema de resolución extrajudicial de conflictos como es el Arbitraje de Consumo.

En aplicación de este Real Decreto, las Juntas Arbitrales que existen en los diferentes territorios de España llevan a cabo mediaciones en materia de consumo, como indica ESTEBAN DE LA ROSA, "tanto en la fase previa al arbitraje como también en la fase de arbitraje (mediación intra-arbitral)", aunque también podrán realizarse por entidades privadas, entre las que destacan las asociaciones de consumidores constituidas en todo el país. Cabe destacar que, en otros países, como Portugal, el sistema arbitral de consumo es llevado a cabo únicamente por entidades privadas autorizadas y financiadas por el Ministerio de Justicia portugués, pero, como afirma de MARQUES CEBOLA, "al ser entidades privadas, sus presupuestos son constituidos, en general, por subvenciones de las entidades asociadas de cada centro". 
La Exposición de Motivos del Real Decreto se abstiene de regular la mediación por congruencia con las competencias autonómicas en esta materia. Sin embargo, refiere que las Juntas Arbitrales de Consumo aseguran el recurso a la mediación previamente al conocimiento del conflicto por los órganos arbitrales. En el mismo sentido, cuando las empresas se adhieran al Sistema Arbitral de Consumo, podrán decidir si aceptan o no la mediación previa. Si no señalaran nada al respecto, se entenderá que aceptan. En la resolución que acuerde el inicio de la actuación arbitral se incluirá la invitación a las partes para alcanzar un acuerdo a través de la mediación previa. Si el reclamado no está suscrito al Sistema Arbitral de Consumo, aún así se le dará traslado por si quisiera aceptar el arbitraje o la mediación. Si no contestará, se archivará la solicitud. También, cuando no existan causas de inadmisión de la solicitud de arbitraje se intentará mediar para que las partes alcancen un acuerdo que ponga fin al conflicto, salvo oposición expresa de cualquiera de las partes o cuando conste que la mediación ha sido intentada sin efecto. La mediación se regirá por la legislación sobre la materia que resulte de aplicación, correspondiendo, no obstante, al secretario de la Junta Arbitral de Consumo dejar constancia en el procedimiento arbitral de la fecha de inicio y fin de la mediación, así como del resultado de esta. En todo caso, quien actúe como mediador en el procedimiento arbitral está sujeto en su actuación a los mismos requisitos de independencia, imparcialidad y confidencialidad exigidos a los árbitros.

La Ley 7/2017, que introdujo el contenido de la Directiva Europea, pese a no regular de forma expresa el procedimiento de mediación en materia de consumo, sí que provocó determinados cambios en su desarrollo. En primer lugar, con anterioridad a la aprobación de esta Ley, ninguna empresa tenía la obligación de contestar a ninguna reclamación de un consumidor ni aceptar ninguna solicitud de mediación. Sin embargo, esto ha cambiado bajo el compromiso de lo dispuesto en la Ley 7/2017, cuyo contenido comenzó a aplicarse en la práctica el día 1 de enero de 2019, de forma que, según su dictado, el empresario que esté adherido a una entidad acreditada en España o en cualquier Estado miembro de la Unión Europea o venga obligado por una norma o código de conducta a aceptar su intervención en la resolución de sus litigios, ha de informar a los consumidores de la posibilidad de recurrir a dicha entidad. Esa información debe incluir la identificación completa de la entidad acreditada, debiendo constar también en las condiciones generales de los contratos de compraventa o de prestación de servicios que el empresario ofrezca al consumidor en el soporte informático que su página web representa. Si ello no fuera posible, se efectuará de cualquier manera que permita al consumidor su conocimiento, en particular a través de folletos informativos propios, carteles con la información en lugar accesible al consumidor o cualquier otra comunicación comercial. En el caso de que la reclamación presentada directamente por el consumidor al empresario no haya podido ser resuelta, éste deberá facilitar al consumidor la información relativa a si se encuentra adherido a una entidad de resolución alternativa de litigios de consumo o si está obligado por una norma o código de conducta a participar en el procedimiento ante una concreta entidad. De no ser así, deberá facilitarle la información relativa, al menos, a una entidad que sea competente para conocer de la reclamación, haciendo la indicación sobre si participará en el procedimiento ante la entidad o entidades indicadas.

Esta información se adecuará en cuanto a su contenido y forma de prestarla a lo previsto la propia Ley 7/2017 y será facilitada en papel o en cualquier otro soporte duradero en el momento de la contestación de la reclamación o en el plazo máximo de un mes desde su interposición si el empresario no hubiera contestado la misma de forma expresa.

En el momento en que el consumidor presente una reclamación ante el empresario (la hoja de reclamaciones), éste siempre tendrá el deber contestar a la misma, se halle o no adherido a una entidad acreditada de solución extrajudicial de conflictos. Podrá responder en el momento o en el plazo de un mes. Por tanto, aunque sigue sin existir una obligación de los empresarios de participar en la mediación en materia de consumo, sí que existe desde ahora una obligación de información que deben dirigir a los consumidores sobre si están o no adheridos a una entidad acreditada. Si estuvieran adheridos, deberán facilitar además toda la información sobre dicha entidad para que 
los consumidores puedan recurrir a la misma. Si no lo estuvieran, aún así, también deberán informar al consumidor sobre la existencia de alguna de estas entidades y sobre si participarán o no en un procedimiento de solución extrajudicial de conflictos.

Podemos afirmar que actualmente poner la hoja de reclamaciones en un establecimiento sería como solicitar la mediación en materia de consumo ya que se inicia el procedimiento extrajudicial de solución del conflicto, que el empresario podrá aceptar o rechazar. Lo que el empresario no podrá rechazar es el sometimiento a arbitraje si se encuentra adherido al Sistema Arbitral de Consumo.

Ahora bien, ¿qué ocurre si el empresario, pese a tener la obligación, se niega a informar al consumidor sobre las entidades acreditadas? Pues para estos casos, la Ley 7/2017 dispone que tal incumplimiento tendrá la consideración de infracción grave en materia de defensa de los consumidores y usuarios, aplicándose lo dispuesto en el régimen sancionador general previsto en el Texto refundido de la Ley General para la Defensa de los Consumidores y Usuarios y otras leyes complementarias, así como en la normativa autonómica correspondiente, sin perjuicio de la existencia de otras posibles infracciones en materia de información al consumidor que vengan tipificadas en la normativa sectorial que resulte de aplicación. En concreto, las sanciones graves en esta materia están recogidas en propio Texto refundido de la Ley General para la Defensa de los Consumidores y Usuarios y otras leyes complementarias y van desde 3.005,07 a 15.025,30 euros.

Por otro lado, también podemos preguntarnos quiénes van a actuar como mediadores. Pues bien, como es de suponer, serán mediadoras las propias entidades acreditadas de conformidad con la Ley 7/2017 así como la propia Junta Arbitral de Consumo, no ostentando las Oficinas Municipales de Información al Consumidor competencias en este sentido. Todas estas entidades podrán mediar entre consumidor y empresario, llegando a proponer soluciones y, en su caso, recogiendo mediante acta el acuerdo final que aquéllos alcancen.

Finalmente, hemos de recordar que el resultado del procedimiento de mediación no será vinculante, es decir, que pese a que finalice con acuerdo entre las partes aceptando alguna propuesta de solución, dicho acuerdo no podrá adquirir el carácter de ejecutivo a no ser que las propias partes opten por ello.

\subsection{Las Oficinas Municipales de Información al Consumidor}

La Constitución Española dispone que los poderes públicos deben garantizar la defensa de los consumidores y usuarios, protegiendo, mediante procedimientos eficaces, la seguridad, la salud y los legítimos intereses económicos de los mismos. Por otro lado, también refiere que promoverán la información y la educación de los consumidores y usuarios, fomentarán sus organizaciones y oirán a éstas en las cuestiones que puedan afectar a aquéllos, en los términos que la ley establezca.

Al no atribuir la Constitución al Estado la competencia exclusiva en materia de defensa de los consumidores, se permite que las Comunidades Autónomas asuman las competencias que no consten expresamente atribuidas al Estado en el precepto anterior. Por tanto, las Comunidades Autónomas ostentan la competencia para gestionar esta materia.

En la Región de Murcia, rige lo dispuesto en la Ley 4/1996, de 14 de junio, del Estatuto de Consumidores y Usuarios de la Región de Murcia, el cual dispone que las administraciones públicas con competencia en esta materia fomentarán la creación de Oficinas de Información al Consumidor. Igualmente señala que se creará, dentro de la Consejería competente, una Oficina

Regional de Información al Consumidor y Usuario para atender a los ciudadanos de localidades donde no exista dichas Oficinas Municipales de Información al Consumidor.

Lo cierto es que gran parte de los Ayuntamientos de la Región han constituido una o varias Oficinas Municipales de Información al Consumidor, como oficinas para ayudar a los 
consumidores a defender sus derechos informándoles, asesorándoles y recibiendo sus reclamaciones en materia de consumo, que irán dirigidas a la Junta Arbitral de Consumo.

La Oficina Municipal de Información al Consumidor informa al consumidor de la posibilidad de acceder a la mediación en materia de consumo con carácter previo a la celebración del procedimiento arbitral, pero no realiza ningún tipo de procedimiento de solución extrajudicial de conflictos en materia de consumo. Por tanto, solamente informa a los consumidores sobre sus posibilidades y sobre los derechos que les conceden las distintas normas sobre protección de los consumidores y usuarios.

Lo cierto es que, desde el 1 de enero de 2019, las Oficinas Municipales de Información al Consumidor ya no recogen solicitudes sobre mediación en materia de consumo, sino que únicamente lo hacen sobre solicitudes de arbitraje ante la Junta Arbitral de Consumo. Desde que se aplica el contenido de la Ley 7/2017, son los propios consumidores los únicos competentes para realizar solicitudes de mediación a través de la presentación de las hojas de reclamaciones ante los empresarios y su posterior tramitación por las entidades acreditadas, quienes resolverán el proceso de mediación si así lo estiman conveniente ambas partes.

\section{CONCLUSIONES}

Actualmente, la figura de la mediación se está convirtiendo, cada vez más, en una herramienta indispensable para la solución ágil y eficaz de las controversias surgidas en el marco de los diferentes ámbitos del ordenamiento jurídico, evitando así los principales inconvenientes que supone acudir a la vía judicial: el excesivo tiempo de espera y la resolución "conflictiva" emanada de una tercera parte ajena al conflicto (el juez).

En el ámbito laboral, debido a la naturaleza negociadora de las relaciones normativas entre empresarios y trabajadores, otorgada a favor de los mismos por la legislación española vigente (sobre todo, por la Constitución Española y el Estatuto de los Trabajadores), es lógico que ellos mismos, a través de sus organizaciones representativas, sean los que identifiquen la mejor forma de solucionar sus conflictos. Para ello, se han llegado a distintos acuerdos que, progresivamente, se van perfeccionando y que pueden aplicarse en distintos ámbitos territoriales o en toda la nación, dependiendo de la esfera geográfica de las organizaciones negociadoras.

Pese a que, a mi parecer, España va por buen camino en el proceso de cimentación normativa de la mediación laboral, todavía queda mucho que hacer, pues la conflictividad judicial en esta materia sigue siendo muy elevada, siendo imprescindible ampliar los medios informativos y los recursos para favorecer la solución extrajudicial de conflictos a través de la mediación. Especial ahínco debería ponerse en la conflictividad individual, pues los medios extrajudiciales de conflictos en materia laboral están dirigidos, prácticamente en su totalidad, a evitar la conflictividad colectiva pero también hay que poner empeño en proteger al trabajador individual y evitarle procedimientos judiciales que en ocasiones pueden tardar años en resolverse.

Por su parte, en cuanto a la mediación en materia de consumo, el Estado es el encargado de elaborar la legislación aplicable. Sin embargo, en la actualidad, existen numerosos vacíos normativos toda vez que no se ha elaborado una legislación que regule de forma específica el procedimiento a seguir en esta materia. La publicación de la Directiva Europea del año 2012 parecía augurar la creación de una normativa estatal que recogiera el régimen jurídico de la mediación a favor de los consumidores pero, no obstante, la normativa llegó tarde y de forma incompleta con la aprobación de la Ley 7/2017, que recogió parcialmente el contenido de la directiva y solamente hizo hincapié en los requisitos para armonizar la calidad de la entidades que, en su caso, participarán en la resolución de los conflictos entre el consumidor y el comerciante. En mi opinión, se desaprovechó una gran oportunidad para elaborar un texto normativo completo y 
actualizado que ofreciera a los consumidores la seguridad jurídica necesaria para solucionar los conflictos que pudieran surgirles de forma ágil e inteligible.

Con anterioridad a la efectiva aplicación de la legislación actual, el día 1 de enero de 2019, se permitía la tramitación de la mediación en materia de consumo ante las Oficinas Municipales de Información al Consumidor. Sin embargo, ahora éstas sólo ofrecen información y son los propios consumidores los que solicitando la "hoja de reclamaciones" en el establecimiento comercial, pueden iniciar el procedimiento de mediación. Parece que condicionar la mediación de consumo a que el consumidor se "enfrente" al empresario no es el medio más adecuado para garantizar la celebración de este procedimiento, por lo que en muchas ocasiones se acaba acudiendo los sistemas arbitrales, siempre que el empresario conste como adherido al Sistema Arbitral de Consumo o así lo decida de forma voluntaria.

\section{BIBLIOGRAFÍA}

ARASTEY SAHÚN, M.L. "La mediación en los conflictos individuales de trabajo", Revista de Jurisprudencia, $n^{\circ}$ 2, Abril 2015.

BALLESTER CASANELLA, B., "Las TIC como instrumento aplicado a la conciliación, mediación y arbitraje en el ámbito laboral ", IDP. Revista de Internet, Derecho y Política $n^{\circ} 25$, Barcelona, 2017, p. 62.

ESTEBAN DE LA ROSA, F., "La vertebración del régimen español de la mediación de consumo en el marco del Derecho europeo", Revista de Internet, Derecho y Política, $\mathrm{n}^{\circ} 25$, septiembre 2017.

FERNÁNDEZ-COSTALES MUÑIZ, J., "Mediación, conciliación y arbitraje en el ordenamiento laboral español. La solución extrajudicial de conflictos laborales en Castilla y León. El acuerdo interprofesional sobre procedimientos de solución autónoma de conflictos laborales (ASACL)", Revista Jurídica de Castilla y León no 50, Valladolid, 2020.

GRANADOS ROMERA, M I., La solución de conflictos colectivos laborales: especial referencia a los sistemas autónomos, Tirant lo Blanch, Granada, 2009.

MARQUES CEBOLA, C., "Mediación y arbitraje de consumo: una visión comparada de los modelos portugués y español", IDP. Revista de Internet, Derecho y Política no 25 , septiembre 2017.

MERCADER UGUINA, J.R., "Relaciones laborales y solución extrajudicial de controversias" en Anuario de la Facultad de Derecho de la Universidad Autónoma de Madrid, no 11, 2007.

MERCADER UGUINA, J. R. y PIÑEYROA DE LA FUENTE, J. A., "El Acuerdo sobre Solución Extrajudicial de Conflictos Laborales: un paso importante en la solución de un problema pendiente", Relaciones Laborales, $n^{\circ}$ 9, 1996.

ORDEÑANA GEZURAGA, I., La conciliación y la mediación en cuanto instrumentos extrajurisdiccionales para solventar el conflicto laboral, Comares, Granada, 2009.

PÉREZ YÁÑEZ, R., "El ASEC: su significado y su recepción en la negociación colectiva”, Revista Española de Derecho del Trabajo, $n^{\circ}$ 98, 1999. 
POSE VIDAL, S. y LÓPEZ ÁLVARES, M.J., "La mediación laboral individual como alternativa para la solución de conflictos", Las medidas preventivas de conflictos jurídicos en contextos económicos inestables, 2014.

ROMERO PRADAS, M.I., “Algunas reflexiones sobre las vías previas al proceso y la solución autónoma del conflicto laboral. Especial consideración de la mediación intrajudicial" en "Nuevos horizontes del derecho procesal", J.M. Bosch Editor, 2019.

TASCÓN LÓPEZ, R., "La solución extrajudicial de conflictos laborales en el modelo español: a medio camino entre el desideratum legal y el ostracismo social», Revista Universitaria de Ciencias del Trabajo $n^{\circ}$ 10, 2009.

VALDEOLIVAS GARCÍA, Y., "El Acuerdo sobre Solución Extrajudicial de Conflictos Laborales: la superación de una asignatura pendiente", en AA.VV. (VALDÉS DAL-RÉ, F., dir.), La reforma pactada de las legislaciones Laboral y de Seguridad Social, Lex Nova, Valladolid, 1997.

VIANA LÓPEZ, C.J., Mediación Laboral, Editorial Dykinson, 2013. 